\title{
SUPERVISORY MANAGEMENT PADA PEMBUATAN LAPORAN STANDAR PELAYANAN MINIMAL (SPM) RUMAH SAKIT
}

\author{
SUPERVISORY MANAGEMENT REPORT TO MAKE MINIMUM SERVICES \\ STANDARD HOSPITAL \\ Cendy Agustin Yudistias \\ Fakultas Kesehatan Masyarakat Universitas Airlangga \\ cendyagustin@gmail.com
}

\begin{abstract}
Services of hospital refers to the Minimum Service Standards for Hospital based KMK No. 129 of 2008. Some of the data service indicators must be made with a frequency of every month. However RSI Jemursari Surabaya had problems regarding the timeliness. To overcome these problems, RSI Jemursari formed a team named champion link. The team was responsible for providing oversight on the accuracy and discipline of the all service's SPM report. This study analyzes the implementation of supervisory management that conducted by champion link based on the assessment of the head unit. This was an observational descriptive research with cross sectional design. Data was collected through questionnaires to all of head unit as many as 24 people. Subjects was selected by total sampling. This research was conducted in RSI Jemursari Surabaya in May, 2016. The result of this study is all stages in supervisory management of SPM report has been accomplished, but not evenly to the all of head unit. The cross tabulation table shows that there is a unidirectional relationship and positive link between the values of supervisory management with head unit's discipline in a report. Conclusions and recommendations of this study is the quality committee and links champion needs to increase and improve the application of supervisory management of SPM report to be able to discipline the all of head unit, not just some head unit.
\end{abstract}

Keywords: discipline, SPM report, supervisory management 


\section{ABSTRAK}

Setiap pelayanan di rumah sakit mengacu kepada Standar Pelayanan Minimal Rumah Sakit berdasarkan KMK Nomor 129 Tahun 2008. Beberapa data indikator pelayanan harus dibuat dengan frekuensi setiap bulan. Namun RSI Jemursari Surabaya mengalami permasalahan mengenai ketepatan waktu pengumpulan laporan SPM. Untuk mengatasi permasalahan tersebut, RSI Jemursari membentuk tim yang diberi nama link champion yang bertanggung jawab memberikan pengawasan pada ketepatan pembuatan laporan SPM seluruh pelayanan. Penelitian ini menganalisis pelaksanaan supervisory management yang dilakukan oleh link champion berdasarkan penilaian dari kepala unit. Penelitian ini merupakan penelitian observasional deskriptif dengan rancang bangun cross sectional. Data diperoleh melalui penyebaran kuisioner kepada seluruh kepala unit sebanyak 24 orang. Metode pengambilan sampel yang digunakan adalah total sampling. Penelitian ini dilakukan di RSI Jemursari Surabaya pada Bulan Mei 2016. Hasil dari penelitian ini adalah seluruh tahapan dalam supervisory management pembuatan laporan SPM telah terlaksana namun belum merata untuk seluruh kepala unit. Tabel tabulasi silang menunjukkan bahwa ada hubungan yang searah dan positif antara nilai yang didapatkan link champion dengan ketepatan waktu kepala unit dalam membuat laporan. Kesimpulan dan saran dari penelitian ini adalah komite mutu RS dan link champion perlu meningkatkan dan memperbaiki penerapan supervisory management pada pembuatan laporan SPM agar dapat mendisiplinkan seluruh kepala unit, bukan hanya beberapa kepala unit saja.

\section{Kata Kunci: kedisiplinan, laporan SPM, supervisory management}

\section{PENDAHULUAN}

Setiap pelayanan di rumah sakit memiliki standar yang digunakan sebagai acuan keberhasilan pelayanan yang ada untuk mencapai pelayanan kesehatan yang optimal bagi seluruh masyarakat penggunanya. Standar tersebut juga digunakan untuk menilai keberhasilan rumah sakit dalam mewujudkan visi dan misi rumah sakit. Sebagai salah satu rumah sakit, Rumah Sakit Islam Jemursari berusaha untuk memberikan pelayanan yang bermutu bagi masyarakat. Indikator keberhasilan setiap pelayanan mengacu kepada Standar Pelayanan Minimal Rumah Sakit yang tertera pada Keputusan Menteri Kesehatan Nomor 129 Tahun 2008 yang selanjutnya disebut dengan SPM KMK No. 129 Tahun 2008. Peraturan tersebut menjelaskan bahwa setiap pelayanan yang ada di rumah sakit mempunyai Standar Pelayanan Minimal. Pihak rumah sakit menggunakan standar tersebut sebagai pedoman dalam menjamin pelaksanaan pelayanan kesehatan.

Jenis pelayanan rumah sakit yang minimal wajib disediakan berdasarkan peraturan tersebut terdiri dari 21 jenis pelayanan. Setiap penanggung jawab atau koordinator pelayanan harus melaporkan hasil pencapaian SPM secara berkala. Namun dalam hal ini, RSI Jemursari Surabaya mengalami permasalahan terkait ketepatan waktu dalam pengumpulan laporan pencapaian SPM. Laporan pencapain SPM hanya akan terkumpul secara lengkap apabila sudah ada himbauan untuk dikumpulkan ke Dinas Kesehatan Kota Surabaya.

Pada Bulan November 2015 jumlah pelayanan yang telah membuat secara tepat waktu hanya sebanyak 10 dari 24 total pelayanan. Hal tersebut menyebabkan kualitas pelaporan data menjadi kurang akurat karena data yang dikumpulkan menjadi data survey bukan data rutin. Padahal seharusnya data laporan tersebut harus akurat untuk menunjang perbaikan dan evaluasi pemberian pelayanan kesehatan di rumah sakit tersebut. Banyak faktor yang dapat menyebabkan masalah keterlambatan pada pembuatan laporan tersebut. Supriyanto (2014), dalam jurnalnya menyebutkan bahwa faktor penyebab digolongkan berdasarkan $5 \mathrm{M}$ yaitu man, machine, method, material, dan management.

Berdasarkan hasil wawancara, komite mutu rumah sakit telah membuat sebuah alur komunikasi yang berisi tentang 
alur pelaporan dan pengawasan dalam hal pembuatan laporan SPM. Melalui pembentukan link champion sebagai penangungg jawab pengawasan pembuatan laporan SPM setiap pelayanan diharapkan dapat meningkatkan ketepatan waktu dalam pembuatan laporan SPM. Alur pelaporan dan pengawasan tersebut menjelaskan bahwa laporan pencapaian SPM yang dibuat oleh kepala unit atau koordinator pelayanan selanjutnya diserahkan ke tim link champion yang kemudian dikumpulkan ke komite mutu rumah sakit.

Berdasarkan penjelasan tersebut, maka yang berperan melakukan supervisory management adalah link champion. Pelaksanaan manajemen pengawasan oleh link champion menjadi sorotan penting karena dengan adanya pengawasan yang baik maka akan berdampak pula pada prestasi kerja para anggota yang diawasi (Rizal, 2013). Apabila tidak ada manajemen pengawasan yang jelas meliputi supervisory planning, organizing, staffing, leading, dan controlling (Newstrom, 2007) mengenai pembuatan laporan pencapaian SPM tersebut, maka keengganan tiap pelayanan untuk membuat laporan akan semakin berlanjut..

Supervisory management disebut sebagai sebuah seni untuk menginspirasi, memberdayakan, dan mengembangkan karyawan (Mosley and Pietri, 2014). Pendapat mengenai definisi dari supervisory management juga datang dari Nelson (2005) yang menjelaskan bahwa supervisory management merupakan aksi mengelola sumber daya manusia agar mampu mengerjakan pekerjaan secara efektif dengan sedikit stress dan tekanan. Supervisory management berbeda dengan manajemen pengendalian (controlling management). Menurut Hämberg (2013) pengawasan lebih berfokus untuk melihat kompetensi SDM, kualitas sebuah kegiatan, dan hasil dari suatu kinerja.

Penelitian ini bertujuan untuk menganalisis penerapan dari seluruh tahapan pada supervisory management pada pembuatan laporan pencapaian SPM. Penelitian ini diharapkan dapat bermanfaat sebagai bahan evaluasi pelaksanaan supervisory management yang memberikan pengaruh pada kualitas pelaksanaan pengawasan secara keseluruhan dalam upayanya meningkatkan ketepatan waktu sebagai indikator kedisiplinan kepala unit dan koordinator pelayanan membuat laporan pencapaian SPM.

\section{METODE PENELITIAN}

Jenis penelitian observasional deskriptif dipilih pada penelitian ini karena bertujuan untuk mendeskripsikan penerapan dari pelaksanaan supervisory management pada pembuatan laporan pencapaian SPM berdasarkan penilaian dari kepala unit atau koordinator pelayanan. Hasil tersebut tidak ditarik kesimpulan yang berlaku untuk umum atau generalisasi. Rancang bangun penelitian ini adalah cross sectional yaitu data yang dikumpulkan pada suatu waktu tertentu untuk menggambarkan keadaan dan kegiatan pada waktu tersebut.

Sumber informasi utama dalam penelitian ini adalah seluruh kepala unit atau koordinator pelayanan yang bertanggung jawab atas penyusunan laporan pencapaian Standar Pelayanan Minimal di RSI Jemursari Surabaya yaitu sebanyak 24 responden. Pendekatan kuantitatif dilakukan untuk melihat penerapan supervisory management pada pembuatan laporan pencapaian SPM. Besar sampel pada penelitian ini diambil dari total populasi yang dipilih berdasarkan kriteria penelitian. Sehingga cara penentuan sampel tersebut dikategorikan secara non probability judgmental sampling.

Penelitian ini dilakukan di 24 pelayanan yang ada di Rumah Sakit Islam Jemursari Surabaya. Tempat ini dipilih karena terdapat indikasi penerapan manajemen pengawasan yang kurang berjalan baik karena belum semua pelayanan mampu untuk membuat laporan pencapaian SPM secara tepat waktu setiap bulan. Penelitian ini dilakukan pada bulan April-Mei 2016.

Tahapan yang dilakukan pada penelitian ini yaitu menggali mengenai gambaran penerapan supervisory management pembuatan laporan SPM berdasarkan penilaian dari kepala unit 
mulai dari tahap pertama yaitu supervisory planning sampai dengan tahap supervisory controlling, selanjutnya menganalisis ketepatan waktu kepala unit dalam membuat laporan SPM berdasarkan hasil penilaian tersebut, kemudian tahap terakhir adalah menarik kesimpulan mengenai penerapan supervisory management pada pembuatan laporan pencapaian SPM di RSI Jemursari Surabaya.

Jenis data yang dikumpulkan pada penelitian ini adalah data primer dan data sekunder. Data primer didapatkan melalui survei kuesioner yang dilakukan kepada responden yang bertanggung jawab dalam membuat laporan pencapaian SPM level unit di RSI Jemursari Surabaya. Instrumen yang digunakan dalam penelitian ini adalah kuesioner mengenai penilaian responden terhadap variabel penelitian. Sedangkan data mengenai hasil ketepatan waktu kepala unit dalam membuat laporan SPM diambil berdasarkan data sekunder yang telah dimiliki oleh komite mutu RSI Jemursari Surabaya.

Teknik perhitungan menggunakan metode kuantitatif dari skala likert sesuai dengan perhitungan dan jumlah pernyataan dari variabel yang bersangkutan. Tiap pernyataan tersebut mempunyai empat jawaban dengan rentang nilai 1 sampai 4 . Hasil nilai disesuaikan dengan skala pengukuran likert yang digunakan melalui kategori rating scale untuk menghasilkan interprestasi. Rating scale ditentukan berdasarkan perhitungan median (nilai tengah). Apabila hasil kurang dari nilai tengah, maka masuk kategori tidak baik. Apabila hasil lebih besar dari nilai tengah, maka masuk kategori baik.

Hasil penilaian tersebut kemudian ditabulasi silang dengan data sekunder yang telah didapat yaitu terkait kedisiplinan kepala unit dalam membuat laporan SPM.

HASIL DAN PEMBAHASAN
Gambaran Umum
Sistem
Pertanggungjawaban Pembuatan
Laporan Pencapaian SPM di Rumah Sakit Islam Jemursari Surabaya

Penelitian ini melibatkan hampir seluruh unit pelayanan yang ada di RSI Jemursari Surabaya. Komite mutu rumah sakit bertanggung jawab atas laporan pencapaian standar pelayanan minimal seluruh pelayanan yang ada di rumah sakit. Sedangkan setiap kepala unit atau koordinator dari setiap pelayanan bertanggung jawab untuk membuat laporan SPM secara tepat. Rumah Sakit Islam Jemursari Surabaya telah mengeluarkan Standard Operational Procedurs (SOP) pembuatan laporan pencapaian SPM yang bertujuan mengatasi ketepatan waktu pengumpulan laporan pencapaian SPM dan juga sebagai syarat akreditasi rumah sakit.

Namun adanya SOP tersebut dinilai masih kurang efektif, sehingga pihak manajemen dan komite mutu memutuskan untuk membentuk sebuah tim yang dinamakan link champion yang bertanggung jawab secara langsung pada pengawasan pembuatan laporan pencapaian SPM seluruh unit. Tim link champion terdiri atas satu orang kepala unit pengadaan, satu orang kepala IFRS dan dua orang koordinator rawat inap yang membawahi kelompok pelayanan yang berbeda. Berikut ini adalah pembagian tanggung jawab link champion untuk setiap kelompok pelayanan tertentu. 
Tabel 1. Pengelompokan Jenis Pelayanan Berdasarkan Pembagian Tanggung Jawab Link Champion

\begin{tabular}{|c|c|c|c|}
\hline Link Champion & Link Champion Medis & $\begin{array}{c}\text { Link Champion } \\
\text { Penunjang }\end{array}$ & $\begin{array}{c}\text { Link Champion Admin \& } \\
\text { Umum }\end{array}$ \\
\hline \multirow{9}{*}{$\begin{array}{l}\text { Jenis } \\
\text { Pelayanan }\end{array}$} & Instalasi Rawat Jalan & Instalasi Farmasi & Bagian Keuangan \\
\hline & Instalasi Rawat Inap & Instalasi Radiologi & Bagian SDM \\
\hline & Instalasi Gawat Darurat & Instalasi Rehab Medik & Bagian Kesekretariatan \\
\hline & Instalasi Bedah & Instalasi Rekam Medik & Bina Rohani \\
\hline & Instalasi Pelayanan & Instalasi Laboratorium & $\begin{array}{l}\text { Unit Pemeliharaan Sarana } \\
\text { RS }\end{array}$ \\
\hline & Intensif & & $\mathrm{RS}$ \\
\hline & Persalinan dan & Instalasi Gizi & Instalasi Laundry \\
\hline & Perinatologi & & Unit K3 \& Kesling \\
\hline & & & Pelayanan Ambulance \\
\hline
\end{tabular}

\section{Karakteristik Kepala Unit Sebagai Penanggung Jawab Penyusunan Laporan Pencapaian Standar Pelayanan Minimal}

Berdasarkan distribusi karakteristik kepala unit diketahui bahwa dari 24 kepala unit yang bertanggung jawab pada pembuatan laporan pencapaian SPM level unit sebagian besar adalah berjenis kelamin perempuan yaitu sebanyak $62,5 \%$ kepala unit, dengan rentang usia antara $36-45$ tahun sebanyak 54,2\% kepala unit. Hal ini menunjukkan bahwa sebagian besar kepala unit termasuk dalam kategori usia dewasa akhir (Depkes RI, 2009), dimana kategori usia tersebut mengartikan bahwa sebagian besar kepala unit yang ada di Rumah Sakit Islam Jemursari Surabaya berada dalam usia yang sangat produktif.

Hasil menunjukkan bahwa sebagian besar pegawai yang diangkat dan dipercaya memegang jabatan sebagai kepala unit adalah mereka yang telah bekerja di RSI Jemursari Surabaya selama lebih dari 10 tahun yaitu sebanyak $62,5 \%$ dan mempunyai pendidikan terakhir Sarjana Strata 1 (S1) sebanyak 41,7\%. Hal ini menunjukkan bahwa kualifikasi pendidikan untuk jabatan kepala unit sebagian besar telah memenuhi Peraturan Menteri Kesehatan Nomor 971 tahun 2009 tentang Standar Kompetensi Pejabat Struktural Kesehatan Pasal 16 yang menjelaskan bahwa Kepala Bagian atau Kepala Bidang harus berlatar belakang pendidikan paling sedikit Sarjana sesuai dengan bidang kerjanya.
Karakteristik dari kepala unit tersebut akan mempengaruhi hasil dari penilaian mereka terhadap penerapan supervisory management pada pembuatan laporan pencapaian SPM.

\section{Analisis Ketepatan Waktu Sebagai Indikator Kedisiplinan Pembuatan Laporan Pencapaian SPM Berdasarkan Hasil Penilaian Kepala Unit Pada Penerapan Supervisory Management}

Analisis ini menggunakan tabulasi silang antara hasil penilaian dari kepala unit untuk link champion mengenai penerapan lima tahapan pada supervisory management dengan hasil ketepatan waktu sebagai indikator kedisiplinan kepala unit dalam membuat laporan pencapaian SPM. Berikut adalah tabel tabulasi silang antara nilai penerapan supervisory management dengan hasil ketepatan waktu kepala unit dalam membuat laporan pencapain SPM di RSI Jemursari Surabaya. 
Tabel 2. Tabulasi Silang Hasil Penilaian Supervisory Management dengan Ketepatan Waktu Pembuatan Laporan SPM Oleh Kepala Unit (April-Mei 2016)

\begin{tabular}{|c|c|c|c|}
\hline \multirow[b]{2}{*}{$\begin{array}{c}\text { Hasil } \\
\text { Penilaian }\end{array}$} & \multicolumn{2}{|c|}{ Ketepatan Waktu } & \multirow[b]{2}{*}{$\begin{array}{c}\text { Total } \\
\mathbf{n} \\
(\%)\end{array}$} \\
\hline & $\begin{array}{c}\text { Tidak Tepat } \\
\mathrm{n} \\
(\%)\end{array}$ & $\begin{array}{c}\text { Tepat } \\
\text { n } \\
(\%)\end{array}$ & \\
\hline \multicolumn{4}{|l|}{$\begin{array}{l}\text { Supervisory } \\
\text { Planning }\end{array}$} \\
\hline Tidak Baik & $\begin{array}{r}2 \\
(100)\end{array}$ & $\begin{array}{r}0 \\
(0)\end{array}$ & $\begin{array}{r}2 \\
(100)\end{array}$ \\
\hline Baik & $\begin{array}{r}7 \\
(31,8) \\
\end{array}$ & $\begin{array}{r}15 \\
(68,2) \\
\end{array}$ & $\begin{array}{r}22 \\
(100) \\
\end{array}$ \\
\hline \multicolumn{4}{|l|}{$\begin{array}{l}\text { Supervisory } \\
\text { Organizing }\end{array}$} \\
\hline Tidak Baik & $\begin{array}{r}3 \\
(100)\end{array}$ & $\begin{array}{r}0 \\
(0) \\
\end{array}$ & $\begin{array}{r}3 \\
(100) \\
\end{array}$ \\
\hline Baik & $\begin{array}{r}6 \\
(28,6)\end{array}$ & $\begin{array}{r}15 \\
(71,4)\end{array}$ & $\begin{array}{r}21 \\
(100) \\
\end{array}$ \\
\hline \multicolumn{4}{|l|}{$\begin{array}{l}\text { Supervisory } \\
\text { Staffing }\end{array}$} \\
\hline Tidak Baik & $\begin{array}{r}2 \\
(66,7)\end{array}$ & $\begin{array}{r}1 \\
(33,3)\end{array}$ & $\begin{array}{r}3 \\
(100) \\
\end{array}$ \\
\hline Baik & $\begin{array}{r}7 \\
(33,3)\end{array}$ & $\begin{array}{r}14 \\
(66,7)\end{array}$ & $\begin{array}{r}21 \\
(100)\end{array}$ \\
\hline \multicolumn{4}{|l|}{$\begin{array}{l}\text { Supervisory } \\
\text { Leading }\end{array}$} \\
\hline Tidak Baik & $\begin{array}{r}5 \\
(83,3)\end{array}$ & $\begin{array}{r}1 \\
(16,7)\end{array}$ & $\begin{array}{r}6 \\
(100)\end{array}$ \\
\hline Baik & $\begin{array}{r}4 \\
(22,2)\end{array}$ & $\begin{array}{r}14 \\
(77,8)\end{array}$ & $\begin{array}{r}18 \\
(100)\end{array}$ \\
\hline \multicolumn{4}{|l|}{$\begin{array}{l}\text { Supervisory } \\
\text { Controlling }\end{array}$} \\
\hline Tidak Baik & $\begin{array}{r}5 \\
(83,3)\end{array}$ & $\begin{array}{r}1 \\
(16,7)\end{array}$ & $\begin{array}{r}6 \\
(100)\end{array}$ \\
\hline Baik & $\begin{array}{r}4 \\
(22,2)\end{array}$ & $\begin{array}{r}14 \\
(77,8)\end{array}$ & $\begin{array}{r}18 \\
(100)\end{array}$ \\
\hline
\end{tabular}

Tabel 2 menunjukan bahwa semakin baik hasil penilaian untuk link champion mengenai penerapan supervisory management, maka semakin baik pula ketepatan waktu kepala unit dalam membuat laporan pencapaian SPM. Sedangkan hasil penilaian untuk link champion yang kurang baik memiliki kecenderungan yang kurang baik pula pada ketepatan waktu kepala unit dalam membuat laporan pencapaian SPM.

\section{PEMBAHASAN}

Tujuan utama dari adanya supervisory management yaitu memastikan bahwa pelaksanaan pengawasan dapat berjalan efektif sehingga mampu membuat tugas atau pekerjaan yang dilakukan oleh para SDM dapat berjalan secara efektif pula. Pada supervisory management, tahapan pada fungsi manajemen (planning, organizing, staffing, leading, dan controlling) memiliki keterkaitan satu sama lain. Keterpaduan fungsi tersebut, memerlukan adanya koordinasi dan tuntutan profesi atas kualitas hasil pengawasan yang menghendaki juga adanya sistem dan program pengendalian mutu dari proses pelaksanaan supervisory management (Indarwati, 2013).

Supervisory planning yang merupakan tahapan pertama dalam supervisory management dianggap sebagai 
tahapan yang terpenting dan berpengaruh pada tahapan-tahapan selanjutnya.

Supervisory Planning merupakan suatu tahapan dalam menentukan mengenai halhal apa yang dilakukan untuk mencapai tujuan dari pengawasan, dimana salah satu tujuan dari pengawasan adalah agar suatu pekerjaan dapat diselesaikan dengan efektif, benar dan tepat waktu, dan disesuaikan pula dengan kebutuhan dari suatu organisasi (Rue and Byars, 2007).

Pada hasil penelitian telah diketahui bahwa penerapan supervisory planning mendapatkan nilai yang paling baik diantara tahapan yang lain. Namun masih ada beberapa kepala unit yang berpendapat bahwa penerapan supervisory planning kurang baik. Apabila dalam pelaksanaan supervisory management, pengawas atau organisasi tidak melakukan tahap supervisory planning dengan baik dan menyeluruh, maka akan mengakibatkan ketidakefektifan dari pelaksanaan pengawasan. Pengawasan yang dilakukan hanya akan menimbulkan masalah dan berjalan tidak efektif.

Seperti yang diungkapkan oleh Mosley dan Pietri (2014) bahwa ketika supervisor hanya sedikit atau bahkan sama sekali tidak melakukan perencanaan pengawasan, maka akan terjadi masalah dan deadline yang tidak terduga, yang mengakibatkan supervisor membuang banyak waktu untuk menyelesaikan masalah tersebut. Pengadaan strategi pengawasan yang wajar dan cocok merupakan unsur penting dalam mengendalikan pekerjaan atau tugas dalam suatu manajemen organisasi (Musa, 2013).

tahap terakhir dalam supervisory management berperan untuk memastikan pelaksanaan pengawasan dapat berjalan dengan efektif sejalan dengan perencanaan yang telah ditentukan dan mengambil tindakan korektif yang diperlukan (Nelson, 2005). Berdasarkan pengertian tersebut dapat diketahui bahwa supervisory planning sangat berpengaruh pada berlangsungnya supervisory controlling. Pembahasan mengenai penilaian kepala unit dalam penerapan supervisory planning pembuatan laporan SPM menunjukkan bahwa strategi pengawasan yang dibuat oleh link champion masih belum merata dan sesuai dengan seluruh kepala unit. Sehingga hal tersebut juga akan berdampak pula pada penerapan supervisory controlling.

Hasil penilaian kepala unit menunjukkan bahwa sebanyak $25 \%$ kepala unit menganggap bahwa penerapan supervisory controlling belum baik. Hal tersebut terjadi karena standar kinerja dari pelaksanaan pengawasan pada pembuatan laporan SPM masih dangkal dan kurang dipahami, sehingga fungsi controlling pada pengawasan juga akan terbatas. Seperti yang dijelaskan oleh The Governor's Office \& The Department of Civil Services, Lousiana State University (2012) bahwa tahap terpenting pada supervisory controlling yaitu evaluasi hasil pelaksanaan pengawasan melalui perbandingan dengan standar dan pengambilan tindakan korektif. Berdasarkan hasil wawancara dengan komite mutu, standar pengawasan yang digunakan selama ini hanya berupa peraturan tertulis dari KMK Nomor 129 Tahun 2008 tentang Standar Pelayanan Minimal Rumah Sakit, selebihnya pelaksanaan pengawasan berjalan apa adanya tanpa ada standar atau SOP. Komite mutu menyadari bahwa adanya sistem pengawasan oleh link champion ini masih baru sehingga membutuhkan banyak koreksi terutama untuk evaluasi pelaksanaan pengawasan. Evaluasi dari hasil pengawasan tersebut seharusnya dapat dijadikan masukan oleh supervisor dan pimpinan untuk menghentikan atau mencegah terulangnya kembali kesalahan penyimpangan, hambatan dan ketidaktertiban tersebut (Lembaga Administrasi Negara RI, 1997).

Sedangkan hasil tabulasi silang antara ketepatan waktu kepala unit dalam membuat laporan pencapaian SPM dengan seluruh penilaian kepala unit mengenai tahapan dalam supervisory management pada pembuatan laporan pencapaian SPM menjelaskan bahwa hasil penilaian yang kurang baik untuk pelaksanaan supervisory management memiliki kecenderungan kurang baik pula dalam memberikan 
pengarahan kepada kepala unit dalam membuat laporan pencapaian SPM secara tepat waktu. Sedangkan hasil penilaian yang baik untuk penerapan supervisory management lebih cenderung mampu untuk meningkatkan ketepatan waktu pembuatan laporan pencapaian SPM.

Hal ini menunjukkan bahwa antara ketepatan waktu pembuatan laporan pencapaian SPM dengan penilaian pada penerapan supervisory management memiliki hubungan yang searah. Penerapan supervisory management yang masih kurang baik memberikan dampak pada ketepatan waktu pembuatan laporan pencapaian SPM.

Dalam melakukan pengawasan yang efektif, para link champion ditantang untuk meningkatkan keterampilan mereka agar mampu menghasilkan produktivitas yang baik dari semua kepala unit yang berada dibawah tanggung jawab mereka. Sebuah pengawasan mempunyai sifat yang kompleks dan menuntut adanya ketrampilan profesional dan interpersonal. Tanggung jawab link champion tersebut adalah untuk melihat apakah seluruh kepala unit telah melakukan pekerjaan mereka dengan baik yaitu terkait pembuatan laporan pencapaian SPM. Layaknya seorang manajer, dalam menjalankan pengawasan, seorang pengawas harus memiliki pengetahuan dan keterampilan dalam hubungan manusia, komunikasi, kepemimpinan, perencanaan dan pengorganisasian (Asgar, J 2008).

\section{SIMPULAN DAN SARAN}

Secara keseluruhan pelaksanaan supervisory management pada pembuatan laporan pencapaian SPM di Rumah Sakit Islam Jemusari Surabaya menghasilkan penilaian yang baik namun masih belum merata pelaksanaannya untuk seluruh kepala unit. Penilaian tertinggi berada pada tahap pertama yaitu superviory planning, sedangkan penilaian terendah berada pada tahap terakhir yaitu supervisory controlling.

Ketepatan waktu sebagai indikator kedisiplinan kepala unit pada pembuatan laporan pencapaian SPM memiliki hubungan searah dengan hasil penilaian untuk link champion pada penerapan supervisory management. Oleh karena itu, upaya perbaikan pada pelaksanaan pengawasan melalui supervisory management diperlukan untuk memperbaiki kedisiplinan seluruh kepala unit dalam membuat laporan pencapaian SPM.

\section{DAFTAR PUSTAKA}

Asgar, J., 2008. The Organizational Role of Supervisions, Fourth Edition. Pratical management, Inc, Florida. USA

Departemen Kesehatan RI 2009 tentang Kategori Penggolongan Usia

Hämberg, Eva (2013). Supervision as control system: the design of supervision as a regulatory instrument in the social services sector in Sweden. Scandinavian Journal of Public Administration. 17(3), 45-64.

Indarwati, M. (2013). Optimalisasi Pengawasan Inspektorat Kabupaten Magelang Dalam Mewujudkan Tata Pemerintahan Yang Baik (Good Governance). Thesis. Universitas Atma Jaya Yogyakarta.

Keputusan Menteri Kesehatan Nomor 129 Tahun 2008 tentang Standar Pelayanan Minimal Rumah Sakit.

Lembaga Administrasi Negara RI., 1997. Sistem administrasi negara RI, Jilid 1 edisi ketiga. Gunung Agung, Jakarta.

Mosley, D.C., dan Piteri, P.H. (2014). Supervisory Management 9th Edition. Cengage Learning

Musa, S.H. (2013). Evaluasi Sistem Pengendalian Manajemen Untuk Meningkatkan Kinerja Manajer Penjualan Pada PT. Hasjrat Abadi Manado. Jurnal Ekonomi dan Pembangunan. Vol.1 No.4. pp 17901798.

Nelson. (2005). The Supervisory Challenge and Management Functions Supervision: Concepts and Practices of Management, 2nd Canadian Edition. Division of Thomson Canada Limited. Canada.

Newstrom, J W., 2007. Supervision: Managing for Results ninth edition, University of Minnesota. Duluth. 
Peraturan Menteri Kesehatan Nomor 971 tahun 2009 tentang Standar Kompetensi Pejabat Struktural Kesehatan

Rizal, S.D. (2013). The Application Of Supervision Has Effect To Employee's Performance At PT. Pos Indonesia (Persero) Head Office Bandung. Skripsi. Universitas Komputer Indonesia, Bandung.

Rue, L.W., dan Byars, L.L. (2007). Supervision: Key Link to Productivity, 9th Edition. McGrawHill Global Education Holdings.

Supriyanto, E. (2014). Analisa Faktorfaktor Penyebab Tidak Lengkapnya Laporan Standar Pelayanan Minimal Rumah Sakit di Rumah Sakit Muhammadiyah Ahmad Dahlan Kota Kediri. Jurnal Kedokteran Brawijaya, Vol. 28, Suplemen No. 1, pp 36-40.

The Governor's Office \& the Department of Civil Service,. (2012) Elements of Supervisory Practices: Part 1. Comprehensive Public Training Program. Office of Human Resource Management. Louisiana State University. 
JURNAL ILMIAH KESEHATAN MEDIAHUSADA | VOLUME 06/NOMOR 01/MARET 2017 